\title{
EXTRACTION AND EVALUATION OF OIL FROM GREEN ALGAE CLADOPHORA GLOMERATA BY HEXANE/ETHER MIXTURE
}

\author{
Adeyinka Sikiru YusufF*, Donatus Ewere
}

\author{
Afe Babalola University, College of Engineering, Department of Chemical and Petroleum Engineering, Afe \\ Babalola Way, Ado-Ekiti, Ekiti State, Nigeria \\ * corresponding author: yusuffas@abuad.edu.ng
}

\begin{abstract}
The overall aim of this study was to grow green algae Cladophora glomerata, extract oil from it, and characterize the extracted oil to gain insight into its physicochemical properties. The effects of parameters affecting the solvent extraction process, temperature, time and biomass particle size were investigated at a fixed solvent ratio of 4:1 hexane to ether. An optimization of oil separation from algae biomass via the solvent extraction method was studied. The obtained results showed that at the extraction temperature of $60^{\circ} \mathrm{C}$, extraction time of $2.5 \mathrm{~h}$, and the particle size of $\leq 0.6 \mathrm{~mm}$, the maximum oil yield was $18.3 \%$ from the process. The functional group analysis revealed the presence of alkane, esters, carboxylic acid, and unsaturated groups on the extracted oil, while the result from the fatty acid profile analysis confirmed the dominance of oleic acid. The physicochemical properties of the extracted algal oil conformed to the ASTM standard.
\end{abstract}

KeYwords: Optimization, extraction, characterization, chlorophyta, microalgae.

\section{INTRODUCTION}

It is no longer news that the use of biofuel as a source of energy has become a significant area of research due to the increase in world population and industries proliferation coupled with expanding economy. Energy, which is one of the famous opportunities and challenges, plays a crucial role in human lives, both socially and economically, and the application of energy today is regarded worldwide as an important factor that determines the extent of a nation development [1, 2. For so many years, fossil fuels, such as coal, natural gas and petroleum have globally been the main sources of energy either for transportation, industrial or domestic purpose [2]. However, the fossil fuels are associated with some demerits, which include depletion and environmental degradation [3. Biofuel provides solutions to the problems of environmental degradation and reserve depletion that are associated with fossil hydrocarbon fuel [3]. These associated problems with fossil hydrocarbon fuels necessitate the need to search for a suitable alternative that would be able to provide solutions for the aforementioned menaces.

Oil derived from plant and animal sources has a great potential toward synthesis of a cleaner and ecofriendly fuel [4] and biofuel such as biodiesel has been produced from three generations of feedstocks. The first generation (G1) biofuel feedstocks are edible crops like groundnut, coconut, soyabean and palm kernel. The synthesis of biofuel from these sources results in food crisis, which would definitely affect the global economy negatively [5]. The second generation (G2) biofuel feedstock is being derived from non-edible sources, such as Jatropha curcas seed, Leucaena leucocephala seed, tobacco seed, rubber seed, animal fat and used cooking/frying oil. The second generation feedstocks have quite a number of advantages over conventional feedstcoks as they guarantee biofuel sustainability and do not lead to a food crisis 6 . However, most of second generation biofuel feedstocks possess high free fatty acid (FFA) content. Thus, biofuel production from these sources may require multiple processes. It will increase the cost of production and may result to wastewater generation [5]. The third generation biofuel feedstocks are regarded as algae (micro and macro algae), which have been considered as a starting ingredient for the bioenergy production and source of industrially important coproducts or value added products [7]. Algae, as a third generation feedstock, have several advantages over the first and second generations feedstocks, which include higher profitability, maximum product yield, neither requiring any land for its cultivation nor cause food shortage [8. All these features coupled with the suitability as feedstock for expansive scale biofuel creation, give the third generation feedstock an edge over G1 and G2 biofuel feedstock [4, 9]. In the present study, green algae chlorophyta, also known as Cladophora glomerata, is chosen as a source of the third generation biofuel feedstock. It can either be found on the shore rocks or on stagnant water, such as ponds and lakes. They possess chlorophyll, carotene, and xanthaphylls which all aid in photosynthesis. It also possesses a cell wall, which contains cellulose and pectins as well as pyrenoid, which helps in the synthesis and deposition of starch [10. The recovery of oil from biomass via a solvent extraction method is considered as one of the most commonly used methods. A solvent extraction is the process in which the oil is removed from a solid by means of a liquid solvent, it 
is also known as leaching [11. Various solvents are used for the extraction, such as organic and inorganic solvents, organic solvents are less dense than water while inorganic solvents are denser than water. Commonly used organic solvents are diethyl ether, toluene, hexane, ethyl acetate, ethanol, and inorganic solvents are dichloromethane, chloroform and carbon tetrachloride [12. The solvent extraction using $\mathrm{n}$-hexane as a solvent results in the highest oil yield, which makes it the most commonly used solvent [11, 13]. Generally, the process of solvent extraction can be considered in three parts: the change of phase of the solute as it dissolves in the solvent, its diffusion through the solvent in the pores of the solid to the outside of the particle, and the transfer of the solute from the solution in contact with the particles to the main bulk [1]. Some reported scientific research studies showed that a solvent extraction using mixture of two or more solvents enhances the extraction yield [1, 4, 10, 14.

The present study was aimed to extract oil from Cladophora glomerata (green algal) via the solvent extraction route. The effects of extraction process parameters, such as extraction temperature, particle size and extraction time, on the oil extraction yield were investigated. The algal oil extracted under the optimum conditions was characterized based on its physicochemical properties, functional groups and fatty acid profile.

\section{MATERIAL AND METHOD}

\subsection{SAMPle CUltivation AND PREPARATION}

The green microalgae Cladophora glomerata was selfcultivated in enclosed plastic containers. The containers were filled with tap water and water containing algae sample collected from Afe Babalola University fish pond, Ado-Ekiti, Nigeria. The water from the fish pond served as nutrient and growth medium for the algae. The enclosed containers were then exposed to sunlight to provide energy required for the growing algae so as to reproduce in the medium. The growth medium was monitored for colour changes and measured weekly to see if there was an increase in weight. Due to the fact that it was microalgae that were being grown, it took weeks before any visible change was observed. After the algae had reached a substantial amount, it was harvested by draining out all the water leaving the algae on the sieve and the harvested algae sample was dried at an ambient temperature for 4 days. The dried algae biomass (AB) was thereafter gently pulverized and later sieved to obtain the required particle size.

\subsection{EXTRACTION STUDIES}

The extraction of oil from the algae biomass was carried out by using a mixture of n-hexane and ether in a mixing proportion of $4: 1$ as solvent. In the present work, the apparatus used was soxhlet extractor. The extractor consists of boiling flask, condenser, thimble and extraction chamber. $25 \mathrm{~g}$ of algae biomass powder was wrapped in a white muslin cloth and placed in a thimble of the extractor. A $250 \mathrm{~mL}$ boiling flask containing the required amount of solvent was gently connected to the end of the extractor and the whole set up was placed on a heating mantle in order to heat up the extractor contents. The extraction processes were performed under these operating conditions: extraction temperatures were $40,50,60,70$ and $75^{\circ} \mathrm{C}$, the extraction times were $1,1.5,2,2.5$ and $3 \mathrm{~h}$ and particle sizes were $0.3,0.4,0.5,0.6,0.7$ and $1 \mathrm{~mm}$. The yield of the extracted oil was gravimetrically evaluated by Eq. (1).

$$
Y=\frac{w_{0}}{w_{A B}} \times 100 \%
$$

where $w_{o}$ is the weight of the extracted oil $(\mathrm{g})$ and $w_{A B}$ is the weight of the algae biomass used (g).

\subsection{Characterization of the And EXTRACTED OIL}

The physicochemical properties, such as specific gravity, $\mathrm{pH}$, acid value, free fatty acid content, iodine value, flash point and pour point were determined according to American Society for Testing and Method (ASTM) and European Union (EU) standard procedures. The functional groups contained in the extracted oil were determined using Fourier transform infrared (FTIR) spectrophotometer (IR Affinity-1S, Shimadzu, Japan). Moreover, a gas chromatography combined with flame ionization detection (GC-FID) (Hewlett Packard 6890S, Palo Alto, USA) analysis was conducted to determine the fatty acid profile of the extracted algal oil.

\section{Results And Discussion}

\subsection{EFFECT OF OPERATING VARIABLES ON ALGAL OIL YIELD}

\subsubsection{EFFECT OF EXTRACTION TEMPERATURE ON OIL YIELD}

Fig. 1 shows the influence of the extraction temperature on the yield of algal oil over the range of $40-75^{\circ} \mathrm{C}$. As can be seen from Fig. 11 the algal oil yield increased with an increasing temperature up to $60^{\circ} \mathrm{C}$ and then dropped as the temperature rose above $60^{\circ} \mathrm{C}$. The reason for this observation is that the temperature enhances the solubility of the oil, which results in a higher extraction rate. The higher oil yield at a higher temperature can also be attributed to the increase in diffusion rate [15]. Another presumed reason for this observation is that when the extraction temperature is increased, the mass transfer of the oil is rapid, which leads to a higher extraction yield. It could, therefore, be deduced that at an optimum temperature of $60^{\circ} \mathrm{C}$, the solubility of the solvent was found to be increased with the increase in diffusion rate [1, 16]. 


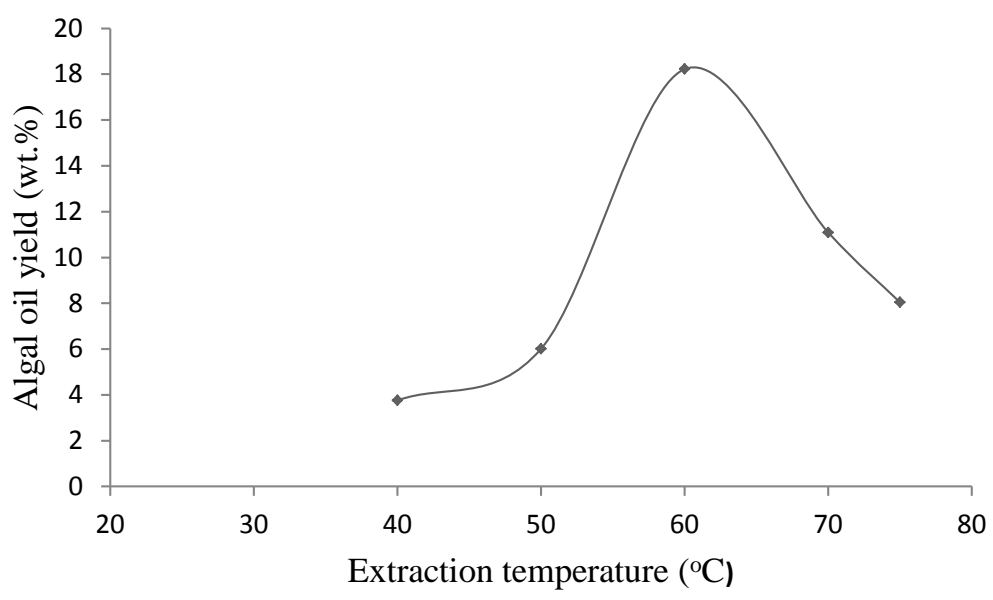

FiguRE 1. Effect of the extraction temperature on algal oil yield at a fixed extraction time $(2 \mathrm{~h})$ and algal particle size $(0.6 \mathrm{~mm})$.

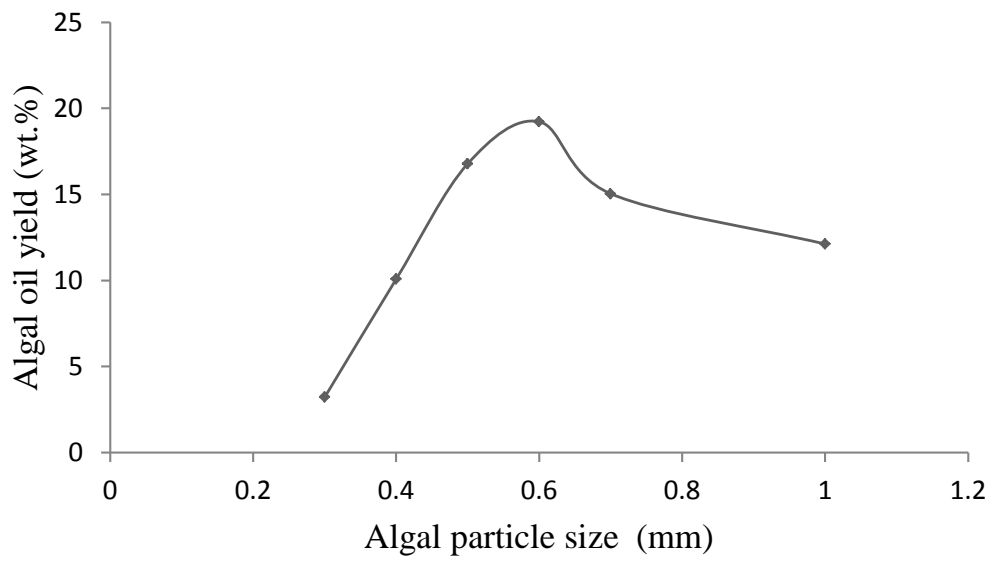

Figure 2. Effect of particle size on algal oil yield at fixed extraction temperature $\left(60^{\circ} \mathrm{C}\right)$ and extraction time $(2 \mathrm{~h})$.

\subsubsection{EFFECT OF PARTICLE SIZE ON OIL YIELD}

To study the influence of particle size on the algal oil extraction yield, each experimental run was conducted at an extraction temperature of $60^{\circ} \mathrm{C}$ for $2 \mathrm{~h}$. The results have been displayed in Fig. 2. This figure shows that the oil extraction yield increases with the particle size up to a maximum of $0.6 \mathrm{~mm}$ and then decreases as the biomass particle size increases. This may be attributed to several factors. At a high particle size, the interfacial area between the solid and solvent becomes lower, and therefore the mass transfer rate of material reduces and this leads to the decrease in the extraction yield. It indicates that, as the particle size increases, the diffusion of the solute within the solid becomes slower [17]. In addition to this, the larger particle size lowers extraction rates as it creates difficulty for the solvent to diffuse through the core of the algal biomass in order to leach the oil (solute). It is observed that the particle size does not only enhance the extraction rate, but also favours the oil extraction yield. This is corroborated by the work reported by Han et al. 18] who showed that the increased oil yield was a direct result of the decrease in particle size, which in turn increases the interfacial surface area of the solute interacting with the solvent. Similar observations were also reported for the oil extracted from marine macroalgae ulva lactuca [16] and green alga Chlorella sp. 9 .

\subsubsection{EFFECT OF EXTRACTION TIME ON OIL YIELD}

Time is one of the important parameters in the extraction process as it helps in deciding the optimum residence time needed for the extraction process [1]. In this study, however, the effect of the extraction time on the oil extraction yield was investigated with different time intervals varying from 1 to $3 \mathrm{~h}$ at a fixed biomass particle size and extraction temperature of $\leq 0.6 \mathrm{~mm}$ and $60^{\circ} \mathrm{C}$, respectively (Fig. 3). The oil yield speedily increased from $7.26 \%$ to $21.82 \%$ with an increase in extraction time from $1 \mathrm{~h}$ to $2.5 \mathrm{~h}$, a higher oil yield was obtained at an extraction time of $2.5 \mathrm{~h}$. However, the oil yield dropped when the extraction time increased beyond $2.5 \mathrm{~h}$. The presumed reason for this observation is that an increase in the extraction time at a high extraction temperature can lead to a low yield of oil. This is probably because the high level of temperature or time is sufficient enough to improve the diffusion coefficient, which would enhance the extraction rate. However, when the extraction is 


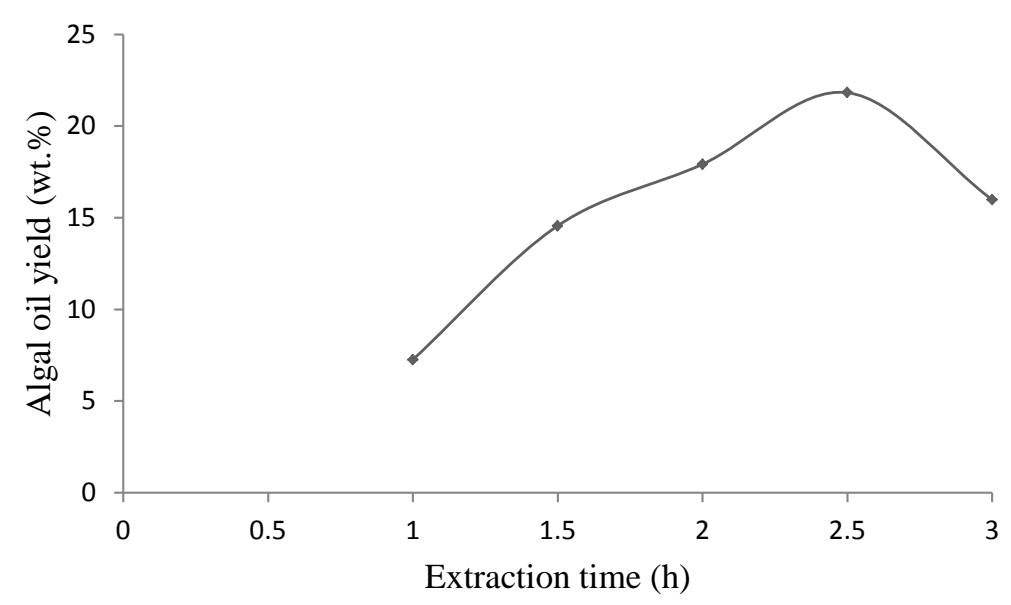

Figure 3. The effect of extraction time on the algal oil yield at a fixed extraction temperature $\left(60^{\circ} \mathrm{C}\right)$ and particle size $(0.6 \mathrm{~mm})$.

\begin{tabular}{lcc}
\hline Parameter & Current study & Reference [4, 10] \\
\hline Colour & Greenish yellow & Greenish yellow \\
Odour & Characteristic odour & NA \\
Specific gravity at $25{ }^{\circ} \mathrm{C}$ & $0.887 \pm 0.02$ & $0.857-0.892$ \\
$\mathrm{pH}$ & $7.18 \pm 0.01$ & 7 \\
Acid value $(\mathrm{mg} \mathrm{KOH} / \mathrm{g}$ oil) & $1.24 \pm 0.13$ & $0.935-14.27$ \\
Free fatty acid $(\mathrm{FFA})$ content $(\mathrm{wt} . \%)$ & $0.62 \pm 0.025$ & $0.468-7.14$ \\
Iodine value $(\mathrm{g} \mathrm{I} / \mathrm{H} / \mathrm{g}$ oil) & $81.27 \pm 0.02$ & $76.24-97.22$ \\
Flash point $\left({ }^{\circ} \mathrm{C}\right)$ & $108 \pm 0.12$ & $110-135$ \\
Pour point $\left({ }^{\circ} \mathrm{C}\right)$ & -16 & -12 to -22 \\
\hline
\end{tabular}

TABLE 1. Physical and chemical properties of the extracted algal oil.

conducted at a high temperature and time, the solvent will form bubbles which inhibit the extraction rate. Hence the extraction time of $2.5 \mathrm{~h}$ was found to be an optimum value.

\subsection{Characterization of the EXtracted ALGAL OIL}

\subsubsection{Physicochemical Properties of the EXTRACTED ALGAL OIL}

To ascertain the quality of the oil extracted from the algae, the physicochemical properties analysis was conducted and the results obtained are presented in Table 1. The value obtained for each property was compared with values reported by previous researchers 4, 16 and the resulting values were found to be in an agreement with the values earlier reported. In addition, the low acid value and FFA content suggest that the extracted oil could be converted directly to biodiesel via single step transesterification. The $\mathrm{pH}$ value of the algal oil was determined to be $7.18 \pm 0.01$ and this indicates that the oil is neutral, which is in an agreement with previous studies on oil extraction from algae by many researchers [4, 19]. The results obtained herein indicate that the algal oil could be used as a low-grade feedstock for biodiesel production and other industrial chemicals where non-edible plant oil can serve as a starting raw material.

\subsubsection{FTIR ANALYSIS}

Fig. 4 shows the FTIR spectrum of the extracted oil from algae biomass. The absorption band between approximately $3100 \mathrm{~cm}^{-1}$ and $3000 \mathrm{~cm}^{-1}$ can be attributed to the $=\mathrm{C}-\mathrm{H}$ stretching from Aromatic, unsaturated hydrocarbons, while the frequency range $2990-2850$ can be ascribed to the $\mathrm{CH}$ stretching in the alkane group. The absorption band at $1748.03 \mathrm{~cm}^{-1}$ confirms the presence of ester groups $(\mathrm{C}=\mathrm{O})$, which indicates that the extracted oil can be transformed into another ester and hence, it can serve as a biodiesel feedstock. The appearance of a trough at $950-1300 \mathrm{~cm}^{-1}$ can be attributed to the $\mathrm{C}-\mathrm{C}(\mathrm{O})$ - C stretching of alcohol and esters. The observed band at around $710 \mathrm{~cm}^{-1}$ is due to the $\mathrm{CH}$ out - of - plane deformation in alkene.

\subsubsection{FATTY ACID PROFILE ANALYSIS}

In addition to the extracted oil quality characterization, the fatty acid profile of the oil was investigated using GC-FID technique. The chromatograms obtained with associated peaks are presented in Table 2 . The main fatty acids in the extracted oil were oleic and stearic acids. This is corroborated by earlier studies on fatty acid profile of algal oil [4, 9, 14, 


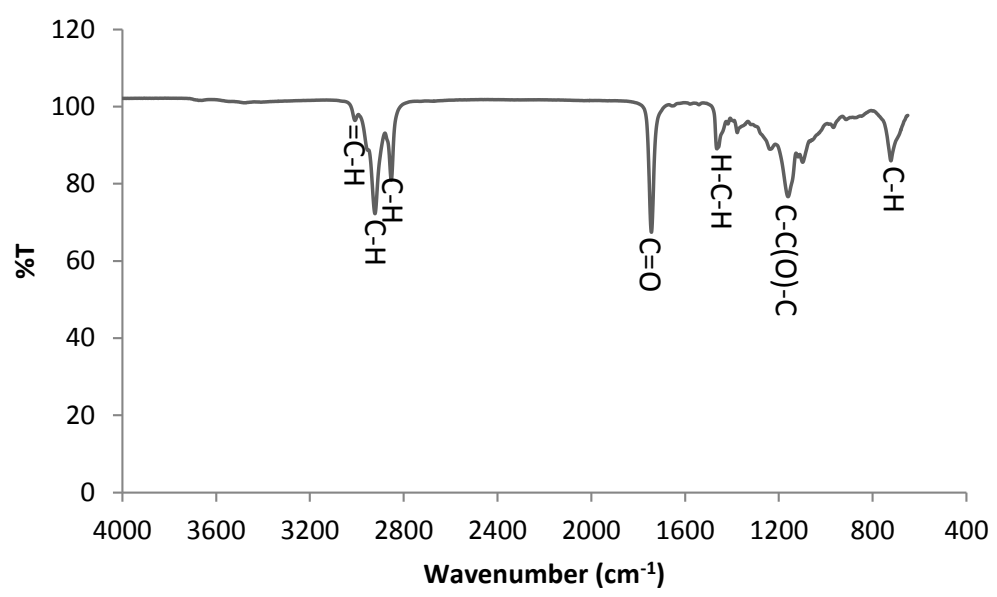

FigURE 4. FTIR spectrum of the extracted algal oil.

\begin{tabular}{lcccc}
\hline Peak no & Retention time $(\mathrm{min})$ & Area $(\%)$ & Fatty acid & Systematic name \\
\hline 1 & 43.315 & 6.96 & Palmitoleic & Hexadecanedoic \\
2 & 47.258 & 69.07 & Oleic & Cis-9-octadecenoic \\
3 & 47.614 & 38.60 & Stearic & Octadecanoic \\
4 & 17.250 & 17.25 & Phthalic & Phthalic \\
\hline
\end{tabular}

TABLE 2. Algal oil fatty acid profile.

\section{Conclusion}

The extraction of oil from green microalgae Cladophora glomerata using a mixture of n-hexane and ether as a solvent was successfully carried out. The effect of extraction process parameters on the algal oil yield was investigated. The maximum oil yield, $18.3 \%$, was found at a particle size of $\leq 0.6 \mathrm{~mm}$, extraction temperature of $60^{\circ} \mathrm{C}$, and extraction time of 2.5 hours. The result of the FTIR analysis confirmed that the extracted oil possessed several functional groups, while the GC-FID analysis conducted that the extracted oil indicated a high oleic acid content. The free fatty acid content of the algal oil was much less, thus making it suitable for a biodiesel production via single-step transesterification.

\section{REFERENCES}

[1] A. Yusuff, M. Lala, L. Popoola, O. Adesina. Optimization of oil extraction from Leucaena leucocephala seed as an alternative low-grade feedstock for biodiesel production. SN Applied Sciences 1:357, 2019. DOI:10.1007/s42452-019-0364-0

[2] A. K. Endalew, Y. Kiros, R. Zanzi. Inorganic heterogeneous catalysts for biodiesel production from vegetable oils. Biomass and Bioenergy 35(9):3787 3809, 2011. DOI:10.1016/j.biombioe.2011.06.011

[3] A. Refaat. Biodiesel production using solid metal oxide catalyst. International Journal of Environmental Science and Technology 8:203 - 221, 2010. DOI:10.1007/BF03326210.

[4] M. Yuvarani, D. Kubendran, A. R. S. Aathika, et al. Extraction and characterization of oil from macroalgae Cladophora glomerata. Energy Sources, Part A:
Recovery, Utilization, and Environmental Effects 39(23):2133 - 2139, 2017. DOI:10.1080/15567036.2017.1400608

[5] K. V. Thiruvengadaravi, J. Nanadagopal, V. S. S. Bala, et al. The solid acid catalyzed esterification of free fatty acids in Pongamia pinnata oil. Energy Sources, Part A: Recovery, Utilization, and Environmental Effects 34(21):2016 - 2022, 2012. DOI: $10.1080 / 15567036.2010 .485176$.

[6] A. Yusuff, O. Adeniyi, M. Olutoye, U. Akpan. Performance and emission characteristics of diesel engine fuelled with waste frying oil derived biodiesel-petroleum diesel blend. International Journal of Engineering Research in Africa 32:100-111, 2017. DOI:10.4028/www.scientific.net/JERA.32.100

[7] T. Mathimani, A. Pugazhendhi. Utilization of algae for biofuel, bio-products and bio-remediation. Biocatalysis and Agricultural Biotechnology 17:326 330, 2019. DOI:10.1016/j.bcab.2018.12.007.

[8] H. Chen, D. Zhou, G. Luo, et al. Macroalgae for biofuels production: Progress and perspectives. Renewable and Sustainable Energy Reviews 47:427 437, 2015. DOI:10.1016/j.rser.2015.03.086

[9] N. Chi, D. Pham, T. Mathimani, A. Pugazhendhi. Evaluating the potential of green alga Chlorella sp. for high biomass and lipid production in biodiesel viewpoint. Biocatalysis and Agricultural Biotechnology 17:184 - 188, 2018. DOI:10.1016/j.bcab.2018.11.011.

[10] M. Abubakar. Extraction and characterization of oil from microalgae through soxhlet extraction method. Bachelor thesis, Afe Babalola University, Ado-Ekiti, Nigeria, 2018.

[11] M. Bhuiya, M. Rasul, M. Khan, et al. Prospects of 2nd generation biodiesel as a sustainable fuel - Part: 1 
selection of feedstocks, oil extraction techniques and conversion technologies. Renewable and Sustainable Energy Reviews 55:1109 - 1128, 2016. DOI:10.1016/j.rser.2015.04.163

[12] S. Mani. Extraction and characterization of Jatropha curcas linnause seed oil through soxhlet method. Bachelor thesis, Universiti Malaysia Pahang, Malaysia, 2016.

[13] A. Atabani, A. Silitonga, I. A. Badruddin, et al. A comprehensive review on biodiesel as an alternative energy resource and its characteristics. Renewable and Sustainable Energy Reviews 16(4):2070 - 2093, 2012. DOI:10.1016/j.rser.2012.01.003

[14] A. Zonouzi, M. Auli, M. J. Dakheli, M. A. Hejazi. Oil extraction from microalgae dunalliela sp. by polar and non-polar solvents. International Journal of Agricultural and Biosystems Engineering 10(10):642 645, 2016. DOI:10.5281/zenodo.1126964.

[15] S. Seth, Y. Agrawal, P. Ghosh, et al. Oil extraction rates of soya bean using isopropyl alcohol as solvent. Biosystems Engineering 97(2):209 - 217, 2007. DOI:10.1016/j.biosystemseng.2007.03.008.
[16] T. Suganya, S. Renganathan. Optimization and kinetic studies on algal oil extraction from marine macroalgae Ulva lactuca. Bioresource Technology 107:319 - 326, 2012. DOI:10.1016/j.biortech.2011.12.045

[17] J. Rodríguez-Miranda, B. Hernández-Santos, E. Herman-Lara, et al. Effect of some variables on oil extraction yield from Mexican pumpkin seeds. CyTA Journal of Food 12(1):9 - 15, 2014. DOI:10.1080/19476337.2013.777123

[18] X. Han, L. Cheng, R. Zhang, J. Bi. Extraction of safflower seed oil by supercritical co2. Journal of Food Engineering 92(4):370 - 376, 2009. DOI:10.1016/j.jfoodeng.2008.12.002

[19] N. Topare, S. Raut, V. Renge, et al. Extraction of oil from algae by solvent extraction and oil expeller method. International Journal of Chemical Sciences 9:1746 - 1750, 2011. 